If clinical medicine is to be formalised as a sequence of decisions, some education of clinicians in the newer way of thinking is necessary. At least one way would be to undertake the kind of study we have described, which forced us to analyse the process of decision making and give numerical estimates to some of the variables. Our experience was most educative and can be recommended.

WIC acknowledges with gratitude a grant from the Scottish Home and Health Department. We are grateful to Professor J P A McManus for help in the early stages of this study.

\section{References}

${ }^{1}$ Weed, L L, Medical Records, Medical Education and Patient Care. Cleveland, Ohio, Western Reserve University, 1969.

${ }^{2}$ Feinstein, A R, Annals of Internal Medicine, 1973, 78, 751.

${ }^{3}$ Lindley, D V, Making Decisions. London, Wiley Interscience, 1971.

4 Card, W I, and Good, I J, in Companion to Medical Studies, ed R Passmore and J S Robson, vol 3, p 60. Oxford, Blackwell Scientific, 1974.

5 Good, I J, and Card, W I, Mathematical Biosciences, 1971, 10, 157

6 Platt, R, Lancet, 1952, 2, 977.

7 Doll, R, Proceedings of the Royal Society of Medicine, 1968, 61, 709.

\title{
Controlled comparison of cimetidine and carbenoxolone sodium in gastric ulcer
}

\author{
S J LA BROOY, R H TAYLOR, R H HUNT, P L GOLDING, J M LAIDLAW, R G CHAPMAN, \\ R E POUNDER, S H VINCENT, D G COLIN-JONES, G J MILTON-THOMPSON, J J MISIEWICZ
}

British Medical fournal, 1979, 1, 1308-1309

\section{Summary and conclusions}

Fifty-four outpatients with endoscopically diagnosed benign gastric ulcer were allocated at random to treatment with either cimetidine $800 \mathrm{mg}$ daily for six weeks or carbenoxolone sodium $300 \mathrm{mg}$ daily for one week then $150 \mathrm{mg}$ daily for five weeks. Ulcers were reassessed by endoscopy at the end of the trial. The endoscopist was unaware of the treatment and did not take part in the clinical care of the patients.

Twenty-one of the 27 patients $(78 \%)$ given cimetidine and 14 of the $27(52 \%)$ given carbenoxolone had healed ulcers. Symptomatic response occurred earlier with cimetidine but was not significantly better. Unwanted effects were more common in the carbenoxolone group: 12 patients developed hypokalaemia, four of whom needed oral potassium supplements.

The results suggest that histamine $\mathrm{H}_{2}$-receptor blockade is at least as effective as carbenoxolone sodium for benign gastric ulcer and produces fewer side effects.

\footnotetext{
Department of Gastroenterology, Central Middlesex Hospital, London NW10 7NS

S J LA BROOY, $M B, M R C P$, research registrar

R H TAYLOR, MB, MRCP, research senior registrar

R E POUNDER, MRCP, DM, research senior registrar (now senior registrar,

St Thomas's Hospital, London)

J J MISIEWICZ, MB, FRCP, consultant physician

Department of Medicine and Gastroenterology, Royal Naval Hospital, Haslar, Hampshire

$S$ H VINCENT, $M B, B S$, registrar

R H HUNT, MB, MRCP, consultant physician

G J MILTON-THOMPSON, MD, FRCP, professor of naval medicine

Department of Gastroenterology, Queen Alexandra Hospital, Portsmouth

P L GOLDING, MB, MRCP, registrar

J M LAIDLAW, MB, MRCP, registrar

R G CHAPMAN, MB, MRCP, registrar

D G COLIN-JONES, MB, MRCP, consultant physician
}

\section{Introduction}

Controlled trials have suggested that carbenoxolone sodium accelerates the healing of gastric ulcer, but side effects limit the $\vec{\varphi}$ freedom with which it may be used, especially in the elderly. ${ }^{2}$ Despite this it has been generally accepted in the treatment of benign gastric ulcer. Early, uncontrolled studies showed that the $\mathrm{H}_{2}$-receptor antagonist cimetidine might be effective in benign gastric ulcer and free of unwanted side effects. ${ }^{3}$ In a later, controlled trial cimetidine was found to be significantly better than a placebo. ${ }^{4}$ We report the results of a controlled study comparing cimetidine $800 \mathrm{mg} /$ day for six weeks with the recommended dose of carbenoxolone sodium in the short-term treatment of benign gastric ulcer.

\section{Patients and methods}

On study day 0 a lesser-curve gastric ulcer was diagnosed endoscopically. Four quadrant biopsy specimens and brush-cytological smears were taken from each ulcer, and blood was obtained for routine haematological and biochemical safety screening. All medication was withdrawn except for a counted supply of unmarked antacid tablets $\mathrm{S}$ containing aluminium hydroxide $180 \mathrm{mg}$ and magnesium hydroxide $N$ $60 \mathrm{mg}$. Patients were instructed in the use of a diary card for the daily recording of daytime and night-time pain and consumption of antacid.

Patients with prepyloric, coexisting duodenal, or postoperative ulcers or whose gastric ulcer was less than $1 \mathrm{~cm}$ diameter (measured $N$ by comparison with an open biopsy forceps) were excluded from the $\underset{\omega}{N}$ study. Also excluded were patients aged 18 years or less, pregnant 0 and lactating women, and patients with hypertension or cardiovascular or renal disease. Those with histopathological or cytological evidence of malignancy or with abnormal laboratory results on the safety $\mathscr{\cap}$ screen were withdrawn.

Patients were seen again on day 7. Those fulfilling the criteria for the trial were allocated at random to treatment with either cimetidine $\frac{\text { Pे }}{\Phi}$ $200 \mathrm{mg}$ four times daily after meals for six weeks or carbenoxolone $\mathcal{O}$ sodium $100 \mathrm{mg}$ thrice daily for one week then $50 \mathrm{mg}$ thrice daily for $\stackrel{\mathbb{Q}}{2}$ five weeks. All patients were seen weekly. At each visit diary cards and unused antacid and trial tablets were collected and a new supply issued. The frequency of pain and antacid consumption were recorded, 8 the patient weighed and examined, and blood obtained for routine haematological and biochemical studies.

Within three days after the end of the six-week course of treatment each patient underwent repeat endoscopy, the result being recorded as "ulcer healed" or "ulcer not healed." The same endoscopist performed both examinations. The endoscopist had no part in clinical management and remained unaware of the patients' treatment. 
Results were analysed using Fisher's exact test of significance for ulcer healing and the Mann-Whitney U test to compare the incidence of pain and antacid consumption in the treatment groups.

\section{Results}

Fifty-seven patients ( 25 women, 32 men) entered the trial. Three were excluded from the analysis: one in each treatment group defaulted, and in the third (given carbenoxolone) gastric cancer was diagnosed histopathologically at the second endoscopy. Four patients did not complete the 42 days of treatment but are included in the analysis. One of these, in the carbenoxolone group, was withdrawn after 24 days because of hypertension. At endoscopy the ulcer was seen to have healed. The other three patients, two given cimetidine and one carbenoxolone, were endoscoped after 35 days because of their holiday arrangements.

Of the 54 patients included in the analysis, 27 received cimetidine and 27 carbenoxolone sodium (see table). The two groups were comparable with respect to age, sex, and duration of disease.

Pain relief-Episodes of pain were noticeably reduced by the end of the first week in patients taking cimetidine and towards the end of the second week in patients taking carbenoxolone (see fig). After six weeks of treatment daytime pain was significantly decreased in both the cimetidine $(P=0.00006)$ and carbenoxolone $(P=0.002)$ groups, there being little change in the incidence of pain at night. There was no significant difference between the two treatment groups except in
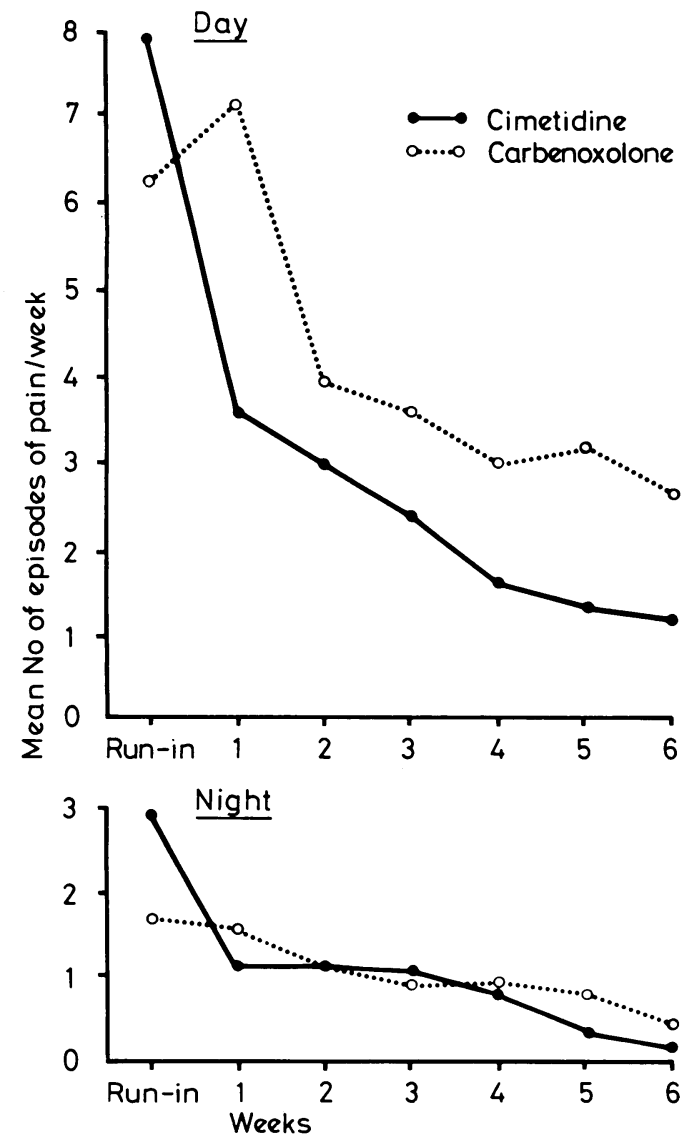

Mean number of episodes of daytime and nocturnal pain in patients treated with cimetidine and carbenoxolone sodium.

week one $(P=0.026)$. Antacid consumption declined in both groups, patients given cimetidine consuming a mean of 35 tablets each and those given carbenoxolone a mean of 44 tablets each during the six weeks; this difference was not significant $(P=0.47)$.

Ulcer healing-Ulcers healed in $21(78 \%)$ patients in the cimetidine group and $14(52 \%)$ in the carbenoxolone group. This difference was not significant $(P=0 \cdot 086)$.
Unwanted effects-Subjective unwanted effects were reported by 10 patients taking cimetidine and 17 taking carbenoxolone sodium. These included dizziness, nausea, vomiting, insomnia, and drowsiness. Two patients taking cimetidine developed a mild acneiform rash but continued with treatment. The rash disappeared when treatment was

Details of treatment groups

\begin{tabular}{|c|c|c|c|c|c|c|c|}
\hline & \multirow[t]{2}{*}{$\begin{array}{c}\text { No of } \\
\text { patients }\end{array}$} & \multicolumn{2}{|c|}{ Sex } & \multicolumn{2}{|c|}{$\underset{\text { (years) }}{\text { Age }}$} & \multicolumn{2}{|c|}{$\begin{array}{c}\text { Duration of } \\
\text { disease } \\
\text { (years) }\end{array}$} \\
\hline & & $M$ & $\mathrm{~F}$ & Mean & Range & Mean & Range \\
\hline $\begin{array}{l}\text { Cimetidine } \\
\text { Carbenoxolone }\end{array}$ & $\begin{array}{l}27 \\
27\end{array}$ & $\begin{array}{l}15 \\
15\end{array}$ & $\begin{array}{l}12 \\
12\end{array}$ & $\begin{array}{l}52 \\
52\end{array}$ & $\begin{array}{l}23-67 \\
31-69\end{array}$ & $\begin{array}{l}3 \cdot 4 \\
3 \cdot 4\end{array}$ & $\begin{array}{l}0-23 \\
0-27\end{array}$ \\
\hline
\end{tabular}

stopped. Six patients developed peripheral oedema during treatment with carbenoxolone, and three of them required thiazide diuretics. Serum potassium concentrations fell to below normal in two patients taking cimetidine but returned to normal during treatment. In contrast, 12 patients in the carbenoxolone-treated group developed hypokalaemia, and in four of these oral potassium supplements were needed. Serum alkaline phosphatase activity was transiently raised (88-104 IU/1) during treatment in nine patients taking carbenoxolone and three taking cimetidine. No patient given cimetidine was withdrawn from the study because of unwanted effects. One patient taking carbenoxolone developed hypertension after 24 days and had to be withdrawn.

\section{Discussion}

The proportion of gastric ulcers healing with cimetidine in this study agrees with findings in studies comparing cimetidine with placebo. ${ }^{4-6}$ In a multicentre $\operatorname{trial}^{5} 70 \cdot 8 \%$ of patients given cimetidine had healed gastric ulcers, which constituted a significant advantage $(P<0.02)$ over placebo. Machell et al reported that $69 \%$ of gastric ulcers had healed at the end of four weeks' treatment with cimetidine and $54 \%$ healed after placebo. The results of Frost et $a l^{4}$ were similar, with $78 \%$ of gastric ulcers healing with cimetidine compared with only $27 \%$ healing with placebo $(\mathrm{P}<0.002)$. In another trial comparison of cimetidine with carbenoxolone just reached conventional levels of significance in favour of cimetidine, but few patients were treated. In that study $41 \%$ of ulcers healed after four weeks of cimetidine $1 \mathrm{~g}$ daily, but all healed after three months of treatment. ${ }^{7}$

In our trial $78 \%$ of gastric ulcers healed with cimetidine and $52 \%$ healed with carbenoxolone sodium. Although this difference is not significant, the unwanted effects of cimetidine were minimal as compared with those of carbenoxolone sodium, $44 \%$ of patients given carbenoxolone developing peripheral oedema or hypokalaemia.

Our results therefore show that cimetidine is at least as effective as carbenoxolone sodium for gastric ulcer and causes fewer unwanted effects.

We thank Ms Christine Ayrton, of Smith, Kline and French, for help with collating the data, and Ms Patricia Evans, Central Middlesex Hospital, for much secretarial work.

\section{References}

1 Doll, R, et al, Lancet, 1962, 2, 793.

2 Langman, M J S, Knapp, D R, and Wakley, E J, British Medical fournal, 1973, 3, 84.

3 Pounder, R E, et al, Lancet, 1976, 1, 337.

${ }^{4}$ Frost, F, et al, British Medical fournal, 1977, 2, 795

5 Bader, J J, et al, in Cimetidine, ed W R Burland and M A Simkinds, p 287. Amsterdam, Excerpta Medica, 1977.

6 Machell, R J, et al, British Medical fournal, 1977, 2, 1023.

${ }^{7}$ Morgan, A G, et al, British Medical fournal, 1978, 2, 1323. 